\title{
Inpatient hyperglycemia management: the opportunities of a new basal insulin
}

\author{
Natalino Simioni \\ General Medicine, Ulss 15 Alta Padovana, Cittadella (PD), Italy
}

\begin{abstract}
The management of hospitalized diabetic patients for any cause is often difficult and affected not only by the comorbidities of the patient but also by the hospital setting. It is well known that at the admission the antidiabetic drugs should be discontinued on behalf of insulin therapy with insulin analogues, as a function of a basal-bolus insulin approach according to the phenotype of the patient, type of nutrition (enteral or parenteral rather than oral), or concomitant hyperglycemic therapy (e.g., steroid). The average stay of diabetic patients hospitalized for any cause is significantly correlated with both the number of hypoglycemia and hyperglycemia. Compared to patients treated with sliding scale patients using a custom algorithm show a significant reduction in the number of hypoglycemia and hyperglycemia episodes and in the length of stay. We analyze the clinical profile of a novel basal insulin, degludec, and explore the potential clinical benefit for diabetic inpatient. The continuation of insulin therapy at home in the immediate post-hospitalization (if necessary), also correlates with a reduction in the rate of re-hospitalization, which combined with close follow-up diabetes can result in a reduction of chronic complications.
\end{abstract}

\section{Background}

In the last years there have been many efforts to find the most suitable management of the diabetic inpatient so to reduce hyperglycemia and hypoglycemia, glycemic variability and length of stay as well. In fact, the research Management of insulin therapy in hospital in PubMed (on date 10/25/2015) generates more

Correspondence: Natalino Simioni, General Medicine, Ulss 15 Alta Padovana, via Casa di Ricovero 40, 35013 Cittadella (PD), Italy.

Tel.: +39.049.9424620 - Fax: +39.049.9424605.

E-mail: natalino.simioni@ulss15.pd.it

Key words: Diabetes mellitus; inpatient hyperglycemia management; insulin degludec.

Funding: editorial assistance was provided by Airon Communications, Milan, Italy, with financial support from Novo Nordisk, in compliance with international guidelines for good publication practice.

Conflict of interest: the author declares no potential conflict of interest.

Received for publication: 22 December 2015.

Revision received: 9 February 2016.

Accepted for publication: 12 February 2016.

This work is licensed under a Creative Commons Attribution NonCommercial 4.0 License (CC BY-NC 4.0).

CCopyright N. Simioni, 2016

Licensee PAGEPress, Italy

Italian Journal of Medicine 2016; 10:103-110

doi:10.4081/itjm.2016.681 than 3000 results, of which 989 reviews, 489 Clinical Trials and 28 guidelines.

Approximately, $38-46 \%$ of non-Intensive Care Unit (ICU) hospitalized patients have diabetes mellitus, either with or without a prior diagnosis. Hyperglycemia is generally associated with an increased risk of mortality, complications and lengths of stays. The mortality rate of in-patients with an hyperglycemia of new diagnosis $(16 \%)$ or with an history of diabetes $(3 \%)$ is higher than hospitalized patients with normoglycemia $(1.7 \%$; both $\mathrm{P}<0.01){ }^{1}$

In hospitalized patients not only hyperglycemia, but also hypoglycemia is associated with an increased risk of mortality, length of stay and complications. The incidence of hypoglycemia (defined as blood glucose levels $\leq 70 \mathrm{mg} / \mathrm{dL}$ ) in patients admitted to general medical wards is between $3.5 \%$ and 10.5 . In patients with diabetes, hypoglycemia can occur in $12 \%-18 \%$, with even higher rates reported when more aggressive antihyperglycemic therapy is used. ${ }^{2}$ Examination of the hourly distribution showed that the majority of hypoglycemic events appeared to occur overnight. This distribution is similar in hypoglycemia spontaneous or associated with antihyperglycemic therapy. ${ }^{3-5}$ Risk factors for nocturnal hypoglycemia include the reduced caloric intake, interruptions in enteral nutrition for scheduled procedures, decreased bedside visits by nursing staff with delayed recognition of hypoglycemic signs and symptoms, and impaired counterregulatory hormone response to hypoglycemia during the sleep. These findings suggest that a heightened vigilance for hypoglycemia may be necessary during nocturnal hours. ${ }^{5}$

Furthermore, patients who had at least one episode 
of hypoglycemia stayed in the hospital 2.8 days longer than patients who did not have any hypoglycemic episodes $(\mathrm{P}<0.0001)$. The difference between actual length of stay (LOS) and LOS expected for the diagnosis related group (DRG) increased gradually from -1.0 days for patients with no hypoglycemia to 8.8 days for patients with $>2$ days with a hypoglycemic episode. Finally, there is an extensive evidence of clinical inertia, defined as failure to initiate or intensify therapy when it is clinically indicated, in the inpatient management and at the time of hospital discharge. ${ }^{6,7}$

The correct balance between glycemic control and hypoglycemia risk reduction is very important to improve inpatient outcomes. The improvement of insulin therapy of hospitalized patients with diabetes and hyperglycemia offers the potential for cost savings from improved hospital outcomes, reduced morbidity and shortened length of stay.

In this review we discussed the current evidence based on the clinical profile of a novel basal insulin, degludec, and explore the potential clinical benefit for diabetic inpatient.

\section{Glycemic management}

An American College of Endocrinology (ACE) position statement in 2004 was followed by a joint consensus statement by the ACE and the American Diabetes Association (ADA) in 2006 advocating standards for diabetes management in the hospital. ${ }^{8}$ The ADA has subsequently published annual recommendations for diabetes care in the hospital as part of its overall position statements on diabetes care based on clinical studies and on expert consensus. Table 1 presents the most recent guidelines for hospitalized patients in the American Association of Clinical Endocrinologists (AACE)/ADA consensus statement. ${ }^{8}$

ADA recommends less stringent blood glucose (BG) targets for critically ill patients, recommends intravenous insulin infusion for critically ill patients and subcutaneous basal-bolus, prandial, and correctional dosing for all non-critically ill patients.

In addition, it emphasizes the importance of glycemic control in the hospital setting and adopts a more vigilant stance towards prevention of hypoglycemia. Generally, the oral hypoglycemic agents should be discontinued at the time of admission and the insulin therapy should be preferentially started. Insulin-treated patients on admission should be revaluated during hospitalization. It is also important to discourage the use of sliding scale insulin therapy. The sliding-scale is an approach in which the short-acting insulin is administered to patients at the moment (when the capillary glucose level is over the target) and without a programmed scheme. Recent evidence for managing glycemic control in hospitalized patients highlighted that a sliding-scale insulin (SSI) approach is not correct and that moving to basal and bolus insulin analogous formulations are helpful for improving the level of glucose control in this setting. Two prospective, randomized, controlled studies in noncritically ill inpatients with hyperglycemia support the concept of optimal glucose management with the basal-bolus scheme (BB). One study showed incremental benefits in glycemic control after switching from SSI to BB and the second study showed a clear improvement in outcomes with a $10 \%$ improvement in patients achieving BG between 160 and $180 \mathrm{mg} / \mathrm{dL}$, a 23\% decrease in length of stay (112 vs $86 \mathrm{~h}$ ), and a decreased need for supplemental insulin ( $8 \%$ of patients down from 29\%). ${ }^{8}$ A recent meta-analysis ${ }^{9}$ of the use of the regular insulin sliding scale (RISS) versus the use of scheduled subcutaneous basal and nutritional (bolus) insulin combined, show that the mean blood glucose level and incidence of hyperglycemic events were significantly higher in the RISS group than in the non-sliding-scale group.

Also in our hospital sliding scale was largely used until 2009: therefore, we have tried to set a personalized insulin scheduled, analyzing existing work in the literature.

For non-ICU patients, the basal bolus insulin method is universally recommended: scheduled subcutaneous insulin therapy consists of a basal or intermediate-acting insulin given once or twice a day in combination with rapid- or short-acting insulin administered before meals in patients who are eating. ${ }^{10}$

In the case of basal insulin development, the challenge has been to retard absorption to a greater extent than occurs with human insulin - ideally to produce a constant, peakless kinetic profile that mimics normal basal insulin secretion.

For basal insulin therapy, neutral protamine Hagerdon (NPH) insulin or long-acting insulin analogue (detemir or glargine) were the three insulin formulations chosen until a short time ago. These products prolonged their action through a variety of mechanisms:

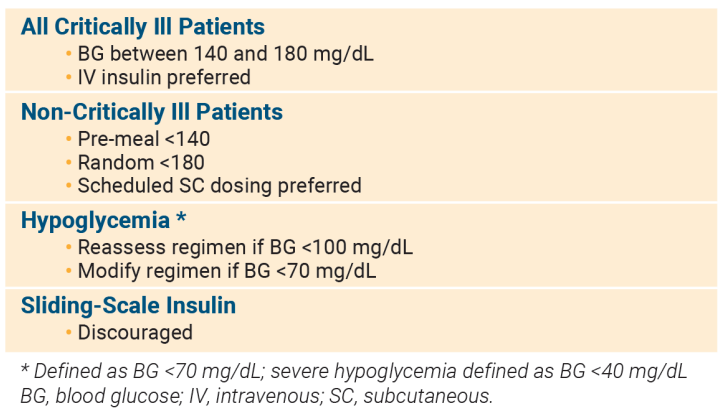

Table 1. Glicemic targets in hospitalized patients. Modified from Moghissi, $2010 .^{8}$ 
crystals depot (NPH insulin), $\mathrm{pH}$ dependent precipitates [insulin glargine (IGlar)] and albumin binding [insulin detemir (IDet)]. Although these mechanisms, the kinetics of these products did not give an ideal absorption profile. The NPH insulin has a pharmacokinetic profile characterised by an inappropriate peak of action coupled with high variability from injection to injection, both of which can lead to hypoglycemia and oblige twice-daily dosing. The two available insulin analogues (insulin glargine and insulin detemir) have improved profiles and have advantages over NPH insulin. Insulin detemir and insulin glargine provide a duration of action lasting 20-24 h with little or no peak, effective and consistent glycemic control, and reduced risks of nocturnal hypoglycemia versus NPH insulin, which has a shorter duration of action that requires twice daily dosing for full 24-h coverage and a higher risk of hypoglycemia because of the sharp peak of insulin concentration 2-4 h after administration. Long-acting insulin analogues are also associated with lower overall BG variability compared to NPH insulin. ${ }^{8}$ However, IDet and IGlar exhibit significant residual within-patient variability in their pharmacokinetic and pharmacodynamic profiles that can lead to less predictable glucose lowering effects, which in turn contributes to the increased risk of hypoglycemia and can undermine dose titration. ${ }^{11}$ Improvements in the pharmacokinetic properties of basal insulin analogues would entail a prolonged duration of action combined with a less variable pharmacodynamic effect, which might lead to more predictable glycaemic control, less hypoglycemia and greater dosing flexibility. ${ }^{11}$

\section{New-generation basal insulin analogue}

Insulin degludec (IDeg) is a new-generation basal insulin analogue. In the presence of phenol and zinc, as in the pharmaceutical formulation, IDeg forms a soluble and stable dihexamer. Following subcutaneous injection and thanks to phenol dispersion, IDeg the dihexamers self-associate to form a stable depot of multi-hexamer chains at the injection site. With the gradual diffusion of zinc, however, these chains are expected to gradually disassemble to release monomers from the terminal ends of multihexamers ${ }^{11,12}$ (Figure 1).

Heise and colleagues, investigated the pharmaco-

\section{FROM INJECTION TO DEPOT}
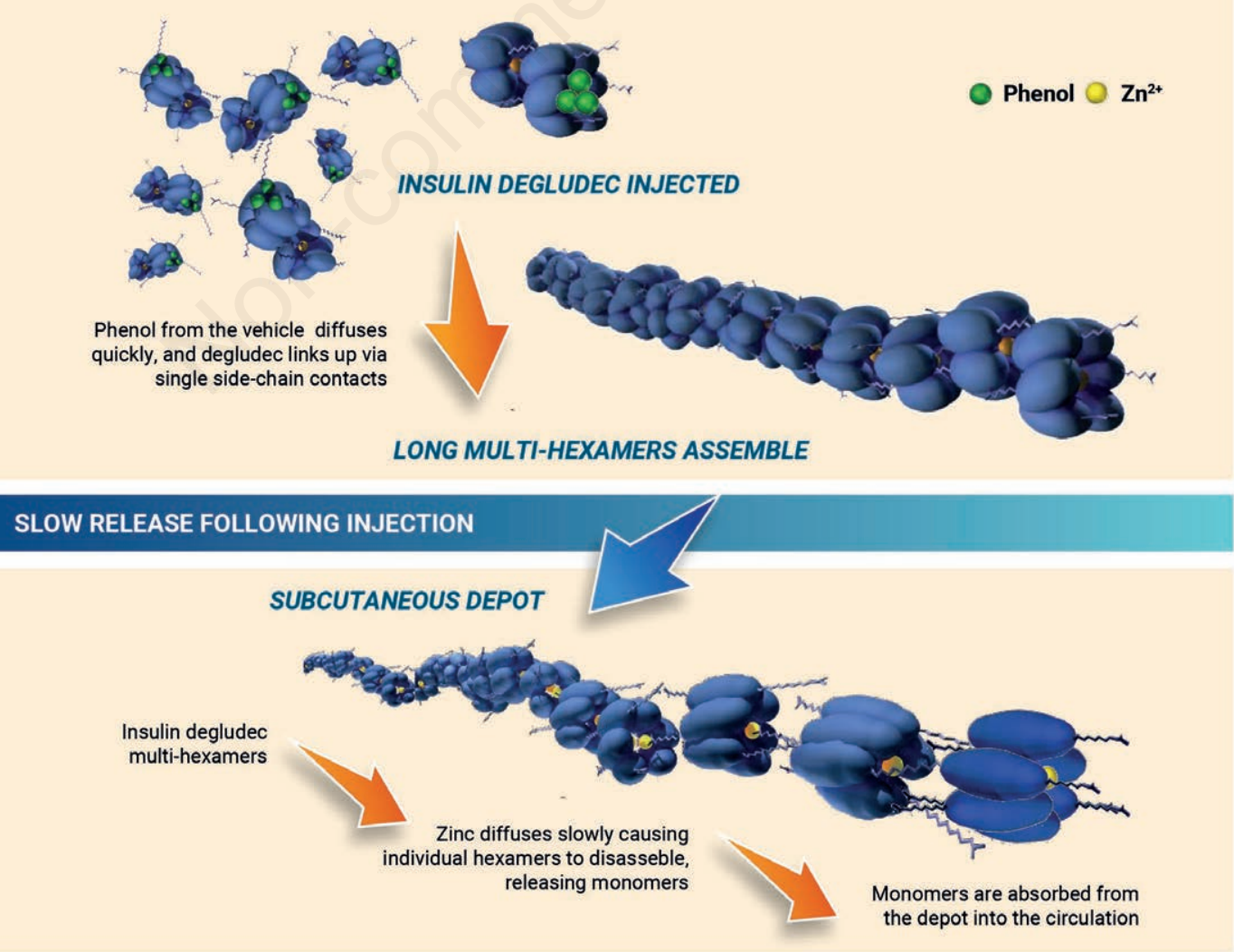

Figure 1. Insulin degludec. DEPOT, deposit; Zn, zinc. Modified from Vora et al., 2015. ${ }^{11}$ 
kinetics and pharmacodinamics properties of this new basal insulin. They demonstrated that the terminal halflife of IDeg was approximately $25 \mathrm{~h}$ at steady state, and total glucose-lowering effect of IDeg increased linearly with increasing dose and extended beyond $26 \mathrm{~h}$. In order to describe the flatness of the pharmacodynamic and pharmacokinetic profile, they compared exposure and the glucose-lowering effect of IDeg in the first $12 \mathrm{~h}$ post-dosing with the following $12 \mathrm{~h}$ of the 24-h dosing interval and observed a nearly perfect split around $50 \%$. Furthermore, the glucose-lowering effect was similar in all the 6-h intervals within the 24-h dosing interval. ${ }^{13}$ In another trial, Heise compared withinsubject day-to-day variability in the glucose-lowering effect of IDeg with IGlar at steady state, and at clinically relevant doses, in subjects with type 1 diabetes. The glucose-lowering action of IDeg at steady state showed four-times lower day-to-day variability during 0-24 $\mathrm{h}$ as compared to IGlar. A flat and stable glucose- lowering effect with IDeg that is evenly distributed across the 24-h dosing interval has also been shown in patients with type 2 diabetes (T2DM) ${ }^{11}$ Importantly, the ultra-long pharmacokinetic and pharmacodynamic properties of IDeg observed in patients with type 1 diabetes (T1DM) and T2DM are maintained in various subpopulations, such as the elderly and those with hepatic or renal impairment (including those with endstage renal disease). ${ }^{11}$

\section{Efficacy and safety of insulin degludec in subjects with diabetes}

The implications of the promising pharmacokinetic and pharmacodynamic characteristics of IDeg have been investigated in a large clinical trial programme (BEGIN) involving more than 11,000 patients with T1DM and T2DM (Table 2): 9 phase 3a

\begin{tabular}{|c|c|c|c|c|c|c|}
\hline $\begin{array}{l}\text { Author } \\
\text { (study name) }\end{array}$ & Population & Trial treatments $(n)$ & Duration & Reduction in $\mathrm{HbA}_{1 \mathrm{c}}$ & Reduction in FPG & $\begin{array}{l}\text { Confirmed hypoglycaemic } \\
\text { episodes }\end{array}$ \\
\hline $\begin{array}{l}\text { Heller et al. } \\
\left.\text { (BEGIN }^{\mathrm{TM}}: \mathrm{T} 1\right)\end{array}$ & $\begin{array}{l}\text { T1DM } \\
\text { insulin-treated }\end{array}$ & $\begin{array}{l}\text { IDeg OD (472) } \\
\text { vs IGlar OD (157) } \\
\text { plus IAsp TID }\end{array}$ & $52 w$ & $\begin{array}{l}\text { IDeg } 0.40 \% \text {; IGlar } 0.39 \% \\
\text { (ETD IDeg vs IGlar - } 0.01 \% \text {; } \\
\text { non-inferior) }\end{array}$ & $\begin{array}{l}\text { IDeg } 1.3 \mathrm{mmol} / \mathrm{L} \text {; IGlar } \\
1.4 \mathrm{mmol} / \mathrm{L}(\mathrm{ETD} \text { IDeg } \\
\text { vs IGlar }-0.33 \mathrm{mmol} / \mathrm{L} ; \\
\mathrm{p}=0.35)\end{array}$ & $\begin{array}{l}\text { IDeg } 43 \text { vs IGlar } \\
40 \text { episodes per PYE; } \\
\text { ERR } 1.07, p=0.48\end{array}$ \\
\hline $\begin{array}{l}\text { Mathieu et al. } \\
\text { (BEGIN }{ }^{\mathrm{TM}} \text { : } \\
\text { Flex T1) }\end{array}$ & $\begin{array}{l}\text { T1DM } \\
\text { insulin-treated }\end{array}$ & $\begin{array}{l}\text { IDeg Forced-Flex OD (164) } \\
\text { vs IDegOD (165) and IGlar } \\
\text { OD, (164) Extension: IDeg } \\
\text { Free-Flex OD vs IGlar OD. } \\
\text { All arms + IAsp TID }\end{array}$ & $\begin{array}{l}26 \mathrm{w} \\
\text { (+ w extension) }\end{array}$ & $\begin{array}{l}\text { IDeg Forced-Flex } 0.40 \% \text {, } \\
\text { IDeg } 0.41 \% \text {, IGlar } 0.58 \% \\
\text { (ETD IDeg Forced-Flex } \\
\text { vs IGlar } 0.17 \% \text {; } \\
\text { non-inferior) }\end{array}$ & $\begin{array}{l}\text { IDeg Forced-Flex } 1.28 \\
\mathrm{mmol} / \mathrm{L} ; \text { IDeg } 2.54 \mathrm{mmol} / \mathrm{L} \text {; } \\
\text { IGlar } 1.33 \mathrm{mmol} / \mathrm{L} \text { (ETD } \\
\text { IDeg Forced-Flex vs IGlar } \\
-0.05 \mathrm{mmol} / \mathrm{L} ; \mathrm{p}=\mathrm{ns}\end{array}$ & $\begin{array}{l}\text { IDeg (including both } \\
\text { Forced-Flex and Free-Flex) } \\
68.1 \text { vs IGlar } 63.4 \text { episodes } \\
\text { per PYE; ERR } 1.09 \text {, } \\
\text { p = ns }\end{array}$ \\
\hline $\begin{array}{l}\text { Garber et al. } \\
\left(\text { BEGIN }^{\mathrm{TM}}: \mathrm{BB}\right)\end{array}$ & $\begin{array}{l}\text { T2DM } \\
\text { insulin-treated }\end{array}$ & $\begin{array}{l}\text { IDeg OD (744) } \\
\text { vs IGlar OD (248) }\end{array}$ & $52 w$ & $\begin{array}{l}\text { IDeg 1.1\%; IGlar: } 1.2 \% \\
\text { (ETD IDeg vs IGlar } \\
0.08 \% \text {; non-inferior) }\end{array}$ & $\begin{array}{l}\text { IDeg } 2.3 \mathrm{mmol} / \mathrm{L} ; \text { IGlar } \\
2.0 \mathrm{mmol} / \mathrm{L}(\mathrm{ETD} \text { IDeg } \\
\text { vs IGlar }-0.29 \mathrm{mmol} / \mathrm{L} \text {; } \\
p=0.1075)\end{array}$ & $\begin{array}{l}\text { IDeg } 11.1 \text { vs IGlar: } \\
13.6 \text { episodes per PYE; } \\
\text { ERR } 0.82, \mathrm{p}=0.0359\end{array}$ \\
\hline $\begin{array}{l}\text { Meneghini et al. } \\
\text { (BEGIN IM: Flex) }\end{array}$ & $\begin{array}{l}\text { T2DM } \\
\text { (insulin-naive } \\
\text { or } \\
\text { insulin-treated }\end{array}$ & $\begin{array}{l}\text { IDeg Flex OD (229), } \\
\text { IDeg OD (228), } \\
\text { IGlar OD (230) }\end{array}$ & $26 w$ & $\begin{array}{l}\text { IDeg Flex } 1.28 \% \text {; } \\
\text { IDeg 1.07\%; IGlar } 1.26 \% \\
\text { (ETD IDeg Flex vs IGlar } \\
0.04 \% \text {; non-inferior) }\end{array}$ & $\begin{array}{l}\text { IDeg Flex } 3.2 \mathrm{mmol} / \mathrm{L} \text {; } \\
\text { IDeg } 3.0 \mathrm{mmol} / \mathrm{L} ; \\
\text { IGlar } 2.8 \mathrm{mmol} / \mathrm{L} \\
\text { (ETD IDeg Flex vs IGlar } \\
-0.42 \mathrm{mmol} / \mathrm{L} ; p=0.04\end{array}$ & $\begin{array}{l}\text { IDeg Flex } 3.6 \text { vs IDeg } 3.6 \\
\text { vs IGlar } 3.5 \text { episodes } \\
\text { per PYE; ERR } 1.03, p=n s\end{array}$ \\
\hline $\begin{array}{l}\text { Zinman et al. } \\
\text { (BEGIN TM: } \\
\text { Once Long) }\end{array}$ & $\begin{array}{l}\text { T2DM } \\
\text { insulin-naive }\end{array}$ & $\begin{array}{l}\text { IDeg OD vs IGlarOD } \\
\text { (+ metformin) }\end{array}$ & $52 w$ & $\begin{array}{l}\text { IDeg } 1.06 \% \text {; IGlar } 1.19 \% \\
\text { (ETD IDeg vs IGlar } 0.09 \% \text {; } \\
\text { non-inferior) }\end{array}$ & $\begin{array}{l}\text { IDeg } 3.8 \mathrm{mmol} / \mathrm{L} \text {; IGlar } \\
3.3 \mathrm{mmol} / \mathrm{L} \text { (ETD IDeg } \\
\text { vs IGlar }-0.43 \mathrm{mmol} / \mathrm{L} ; \\
\mathrm{p}=0.005)\end{array}$ & $\begin{array}{l}\text { IDeg } 1.52 \text { vs IGlar } \\
1.85 \text { episodes per PYE; } \\
\text { ERR } 0.82, p=0.103\end{array}$ \\
\hline $\begin{array}{l}\text { Gough et al. } \\
\text { (BEGIN TM: } \\
\text { LOW VOLUME) }\end{array}$ & $\begin{array}{l}\text { T2DM } \\
\text { insulin-naive }\end{array}$ & $\begin{array}{l}\text { IDeg } 200 \mathrm{U} / \mathrm{mL} 0 D \\
\text { vs IGlar OD (+ metformin } \\
\pm \text { dipetidyl peptidase) }\end{array}$ & $26 w$ & $\begin{array}{l}\text { IDeg } 1.3 \% \text {; IGlar } 1.3 \% \\
\text { (ETD IDeg vs IGlar } 0.04 \% \text {; } \\
\text { non-inferior) }\end{array}$ & $\begin{array}{l}\text { IDeg } 3.7 \mathrm{mmol} / \mathrm{L} \text {; IGlar } \\
3.4 \mathrm{mmol} / \mathrm{L} \text { (ETD IDeg } \\
\text { vs IGlar }-0.42 \mathrm{mmol} / \mathrm{L} ; \\
p<0.05)\end{array}$ & $\begin{array}{l}\text { IDeg } 1.22 \text { vs IGlar } \\
1.42 \text { episodes per PYE; } \\
\text { ERR } 0.86, p=0.046\end{array}$ \\
\hline $\begin{array}{l}\text { Onishi et al. } \\
\text { (BEGIN }{ }^{\mathrm{TM}} \text { : } \\
\text { ONCE ASIA) }\end{array}$ & $\begin{array}{l}\text { T2DM } \\
\text { insulin-naive }\end{array}$ & $\begin{array}{l}\text { IDeg OD vs Glar OD } \\
\text { (+ oral antidiabetic } \\
\text { drugs) }\end{array}$ & $26 w$ & $\begin{array}{l}\text { IDeg } 1.24 \% \text {; IGlar } 1.35 \% \\
\text { (ETD IDeg vs IGlar } 0.11 \% \text {; } \\
\text { non-inferior) }\end{array}$ & $\begin{array}{l}\text { IDeg } 2.88 \mathrm{mmol} / \mathrm{L} \text {; IGlar } \\
2.97 \mathrm{mmol} / \mathrm{L}(\mathrm{ETD} \text { IDeg } \\
\text { vs IGlar }-0.09 \mathrm{mmol} / \mathrm{L} ; \\
\mathrm{p}=0.59)\end{array}$ & $\begin{array}{l}\text { IDeg } 3.0 \text { vs IGlar } 3.7 \\
\text { episodes per PYE; } \\
\text { ERR } 0.82, p=0.20\end{array}$ \\
\hline $\begin{array}{l}\text { Philis-Tsimikas } \\
\text { et al. (BEGIN }{ }^{\mathrm{TM}} \text { : } \\
\text { EARLY) }\end{array}$ & T2DM & $\begin{array}{l}\text { IDeg OD vs sitagliptin } \\
\text { (+ oral antidiabetic drugs) }\end{array}$ & $26 w$ & $\begin{array}{l}\text { IDeg } 1.52 \% \text {; sitagliptin } \\
1.09 \% \text { (ETD IDeg vs } \\
\text { sitagliptin } 0.43 \% \text {; } \\
\text { superior) }\end{array}$ & $\begin{array}{l}\text { IDeg } 3.41 \mathrm{mmol} / \mathrm{L} \text {; } \\
\text { sitagliptin } 1.24 \mathrm{mmol} / \mathrm{L} \\
\text { (ETD IDeg vs sitagliptin } \\
-2.17 \mathrm{mmol} / \mathrm{L} \text {; superior) }\end{array}$ & $\begin{array}{l}\text { IDeg } 3.1 \text { vs sitagliptin } \\
1.3 \text { episodes per PYE; } \\
\text { ERR } 3.81, \mathrm{p}=\mathrm{nr}\end{array}$ \\
\hline
\end{tabular}

ERR, estimated rate ratio; ETD, estimated treatment difference; FPG, fasting plasma glucose; IAsp, insulin aspart; IDeg, insulin degludec; IGlar, insulin glargine $n r$, not reported; $n s$, not significant: PYE, patient-year of exposure; OD, once daily: TID three times daily: T1DM, type 1 diabetes mellitus: T2DM, type 2 diabetes mellitus; $w$, weeks. Trials shaded in blue were included in the meta-analysis of hypoglycaemia rates, published by Ratner et al. except the extension of the BEGIN Flex $T 1$ trial, which was not included in the meta-analysis.

Table 2. Summary of the phase 3a clinical trials in the BEGIN ${ }^{\mathrm{w}}$ clinical programme with insulin degludec. Modified from Vora et al., 2015.11 
randomised, controlled, open-label, multicentre trials with a treat-to-target design (in order to meet Food and Drug Administration recommendations for noninferiority of new insulins) have been carried out. ${ }^{11}$ In all studies, insulin dose titration included adjustment of insulin doses to achieve pre-breakfast self-measured blood glucose values of 4-5 $\mathrm{mmol} / \mathrm{L}$ (70-90 $\mathrm{mg} / \mathrm{dL}$ ). In addition, the same definition of confirmed hypoglycemia [plasma glucose $<3.1 \mathrm{mmol} / \mathrm{L}(<56$ $\mathrm{mg} / \mathrm{dL}$ ) or severe hypoglycemia] was used throughout the programme. ${ }^{11}$ This definition of hypoglycemia (that is, a low hypoglycemia cut-off level due to the low target plasma glucose level) was chosen to avoid false positives and to discriminate hypoglycemia with neuroglycopenic symptoms. Similarly, nocturnal hypoglycemia was defined as confirmed episodes of hypoglycemia occurring between 00:01 $\mathrm{h}$ and 05:59 h, in order to minimize confounding by any hypoglycemia related to the prandial insulin component in the basal-bolus studies. ${ }^{11}$

Hollander and colleagues tested long-term safety and efficacy of insulin degludec in basal-bolus scheme. Advanced T2DM patients were randomised to once-daily IDeg or IGlar, with mealtime insulin aspart \pm metformin \pm pioglitazone, and titrated to prebreakfast plasma glucose values of 3.9-4.9 mmol/L. Mean glycosylated hemoglobin ( $\mathrm{HbA1c}$ ) values decreased from $8.2 \%$ at baseline to $7.2 \%$ after 78 weeks of treatment with IDeg and from $8.3 \%$ to $7.1 \%$ with IGlar and central laboratory measured fasting plasma glucose (FPG) decreased by $2.4 \mathrm{mmol} / \mathrm{L}(43 \mathrm{mg} / \mathrm{dL})$ after 78 weeks of treatment with IDeg and by 2.2 $\mathrm{mmol} / \mathrm{L}(40 \mathrm{mg} / \mathrm{dL})$ with IGlar. This study demonstrated that patients with advanced T2DM who continued IDeg therapy experienced long-term improvements in glycemic control similar to those of patients treated with IGlar at comparable doses, but with lower risk of overall and nocturnal confirmed hypoglycaemia, with a reduction of $24 \%$ with IDeg than IGlar [estimated rate ratio (ERR) IDeg/IGlar: 0.76 $(0.62 ; 0.94) 95 \%$ confidence interval $(\mathrm{CI}), \mathrm{P}=0.011]$ and $31 \%$ lower with IDeg than IGlar [ERR: 0.69 $(0.51 ; 0.93) 95 \% \mathrm{CI}, \mathrm{P}=0.016]$ respectively. The mean daily basal insulin dose was $0.76 \mathrm{U} / \mathrm{kg}$ and $0.71 \mathrm{U} / \mathrm{kg}$ in the IDeg and IGlar groups, respectively, after 78 weeks; mean daily bolus insulin doses were: 0.21 $\mathrm{U} / \mathrm{kg}$ and $0.23 \mathrm{U} / \mathrm{kg}$ at breakfast, $0.25 \mathrm{U} / \mathrm{kg}$ and 0.26 $\mathrm{U} / \mathrm{kg}$ at lunch, and $0.29 \mathrm{U} / \mathrm{kg}$ and $0.30 \mathrm{U} / \mathrm{kg}$ at the main evening meal. ${ }^{14}$

Also the study in T2DM insulin-naive subjects confirmed that IDeg is non-inferior to IGlar in terms of reducing $\mathrm{HbA} 1 \mathrm{c}$ concentrations. Clinical data from insulin-naive patients with T2DM also indicate that, as seen in T1DM studies, nocturnal confirmed hypoglycemia and the total daily insulin dose at the end of the trial were lower in subjects who received IDeg compared with those who received IGlar. There was also a trend towards lower FPG levels with IDeg compared with IGlar in five trials with T2DM, which reached statistical significance in three of them. ${ }^{14}$

Ratner and coll. recently published a meta-analysis about the reduction in the risk of hypoglycemia with insulin degludec, based on prior discussions with and subsequent review by regulatory authorities prior to the unblinding of data for the individual trials. The reduction in the risk of overall and nocturnal hypoglycemia with IDeg compared to IGlar was correctly established at equivalent $\mathrm{HbA} 1 \mathrm{c}$ levels. Changes in hypoglycemic rates across the study timeline were compared between treatments during the titration period ( $0-15$ weeks of treatment) and the maintenance period (from 16 weeks to the end of treatment). The meta-analysis confirmed that there is a statistically significant reduction in risk of overall hypoglycemia and nocturnal hypoglycemia with IDeg compared to IGlar across the entire treatment period. In the population of subjects with T2DM, the rates of overall and nocturnal confirmed hypoglycemia were: $17 \%$ and $32 \%$ lower, respectively, across the entire treatment period; $25 \%$ and $38 \%$, respectively, during the maintenance phase. ${ }^{15}$

This pre-planned meta-analysis shows that similar improvements in $\mathrm{HbA} 1 \mathrm{c}$ can be achieved with fewer hypoglycemic episodes, particularly nocturnal episodes, with IDeg than with IGlar across a broad spectrum of patients with diabetes (particularly T2DM patients), and insulin regimens. ${ }^{15}$

Long-acting insulin analogues have been developed to cover the basal requirements of patients with diabetes but current treatment options generally require sometime-daily (or even twice-daily) administration to ensure optimal glycemic control. This schedule is often in conflict with everyday variations in patients' lives and can be challenging for patients. Findings suggest that missing or delaying injections is relatively common and may result in deterioration of glycemic control. Many patients with diabetes report missing numerous injections, resulting in a significant association between self-reported noncompliance and higher $\mathrm{HbAlc}$ levels. Insulin omission frequency can be significantly affected by perceived burden of therapy. Greater flexibility in daily injections may thus benefit all insulin-treated patients who often need to adjust dosing times. ${ }^{16-21}$ This is important in hospital setting, for the management by nurses and doctors of diabetic inpatients.

Mathieu and coll. investigated the efficacy and safety of IDeg once daily (OD), varying injection timing day to day in 493 subjects with type 1 diabetes. This was a novel trial both for investigators and participants because it challenged deeply ingrained habits by asking people with long-standing T1DM to inject basal insulin at varying daily time points while simultaneously aim- 
ing for the ambitious FPG targets considered attainable given IDeg's pharmacokinetic profile.

This 26-week, open-label, treat-to-target, non-inferiority trial compared IDeg forced flexible (ForcedFlex) OD (given in a fixed schedule with a minimum 8 and maximum $40 \mathrm{~h}$ between doses) with IDeg or IGlar given at the same time daily OD. In the 26-week extension, all IDeg subjects were transferred to a freeflexible (Free-Flex) regimen, which allowed any-timeof-day dosing, and compared with subjects continued on IGlar. There was no difference in observed mean decrease in $\mathrm{HbA} 1 \mathrm{c}$ from baseline to week 26 between IDeg Forced-Flex ( $-0.40 \%$ points $)$ and IDeg $(-0.41 \%$ points). Laboratory-measured FPG decreased from baseline to week 26 (IDeg Forced-Flex, -1.28; IDeg, -2.54 ; IGlar, $-1.33 \mathrm{mmol} / \mathrm{L}$ ), with the most pronounced decline occurring during the first 12 weeks. No significant difference was seen with IDeg ForcedFlex vs IGlar, but a greater reduction was seen with IDeg than with IDeg Forced-Flex [(IDegForced-FlexIDeg): $0.95 \mathrm{mmol} / \mathrm{L}(0.15 ; 1.75) 95 \% \mathrm{CI}, \mathrm{P}=0.021] .{ }^{22}$ IDeg Free-Flex was not significantly different from IGlar in lowering HbA1c at week 52, with an upper 95\% CI limit below a predefined non-inferiority mark of $0.4 \%$. Mean FPG decreased from baseline to week 52 with IDeg Free-Flex $(-1.73 \mathrm{mmol} / \mathrm{L})$ and IGlar $(-0.61 \mathrm{mmol} / \mathrm{L})$, with a significantly greater reduction observed with IDeg Free- Flex: $-1.07 \mathrm{mmol} / \mathrm{L}$ ( -1.82 ; $-0.32) 95 \% \mathrm{CI}, \mathrm{P}=0.005] .{ }^{22}$ The proportion of participants who attained pre-breakfast self-monitoring plasma glucose $<5.0 \mathrm{mmol} / \mathrm{L}$ at week 52 was $17.9 \%$ (IDeg Free-Flex) and 13.8\% (IGlar). At week 52, mean daily basal, bolus, and total insulin doses were lower by $4 \%, 18 \%$, and $11 \%$, respectively, with IDeg Free-Flex $v s$ IGlar. The greater mean total daily insulin dose with IGlar vs IDeg Free-Flex was due mainly to a decrease in mean daily bolus insulin dose with IDeg Free-Flex $(0.39$ to $0.35 \mathrm{U} / \mathrm{kg})$ and an increase with IGlar $(0.40$ to $0.42 \mathrm{U} / \mathrm{kg}){ }^{22}$

The nocturnal confirmed hypoglycemia rate was significantly lower with IDeg Forced-Flex than IGlar [by 40\%; (IDegForced-Flex/Iglar): 0.60 (0.44; 0.82) $95 \% \mathrm{CI}, \mathrm{P}=0.001$ ] and IDeg [by 37\%; (IDegForcedFlex/IDeg): $0.63(0.46 ; 0.86) 95 \% \mathrm{CI}, \mathrm{P}=0.003]$. Nocturnal confirmed hypoglycemia rates were generally lower with IDeg Forced-Flex than with IGlar and IDeg, regardless of the day of the week. In the 52week extension trial, Nocturnal confirmed hypoglycemia rates were significantly lower with IDeg Free-Flex by $25 \%$ [ERR (IDegFree-Flex/IGlar): 0.75 $(0.58 ; 0.97) 95 \% \mathrm{CI}, \mathrm{P}<0.026]$. Full-year results confirmed findings from the 26-week main trial, with the extension allowing all IDeg subjects the option to dose more flexibly than at same time daily. ${ }^{22}$

This concept of flexibility was also tested in patients with T2DM and the large variation in the injec- tion time of IDeg did not compromise its efficacy or safety when compared to IGlar taken at the same time each day. ${ }^{23}$

Anticipating or delaying a scheduled daily dose of basal insulin will affect its concentration in the circulation; however, this effect will be less for insulin preparations, such as IDeg, with a longer half-life and duration of action. ${ }^{24}$ IDeg should be administered once-daily, however, on occasions when administration at the same time of the day is not possible or in the event of a missed dose, IDeg allows for flexibility in the timing of dose administration provided a minimum of $8 \mathrm{~h}$ between injections is ensured. ${ }^{25}$ The broader dosing window for IDeg can allow more flexibility in the timing of insulin administration during the management of hyperglycemic inpatients and it may allow patients after discharge to use a more convenient injection schedule without compromising either control of blood glucose levels or safety.

Several recent papers have demonstrated the costeffectiveness of IDeg compared to IGlar. A cost-utility model based on both data from a meta-analysis of phase 3 trials and a questionnaire-based study conducted in Sweden, reported that IDeg was associated with greater quality adjusted life year (QALY) gains in patients with T1DM (0.31 vs 0.26 QALYs gained for IGlar), patients with T2DM requiring basal insulin (0.76 vs 0.69 QALYs gained) and patients with T2DM requiring basal-bolus treatment ( 0.56 vs 0.47 QALYs gained) after one year of treatment. ${ }^{26}$ While pharmacy costs for IDeg were higher, these were partially offset by cost savings due to reduced insulin doses, reduced direct costs of hypoglycemia, reduced productivity losses and reduced costs of blood glucose monitoring. ${ }^{26}$ Similarly, two UK-based studies examined cost-utility of IDeg compared to IGlar in the context of the UK national health service, in patients with T1DM and T2DM, using hypoglycemia rates for IDeg and IGlar from a pre- planned metaanalysis of phase III clinical trials. In both studies, IDeg was within the previously reported willingnessto-pay threshold of $£ 20,000$ to $£ 30,000$ per QALY. Of note, sensitivity analyses demonstrated that using higher baseline non-severe hypoglycemic events resulted in greater cost-effectiveness for IDeg compared to IGlar. ${ }^{27,28}$

Clinical evidence from the clinical trial programme have demonstrated that IDeg provides effective glycemic control, similar to that observed with IGlar, but with lower rates of hypoglycemia, in particular nocturnal hypoglycemia, and a flexibility in dose timing. Furthermore, our clinical experience (unpublished data) confirms that insulin degludec could be a useful option for providing glycemic control in type 2 diabetic inpatients with hyperglycemia, in order to manage hyperglycemia, hypoglycemic episodes and 
ward needs. A retrospective analysis of our data will be submitted to the journal in the next months.

\section{Conclusions}

Diabetes is an increasingly prevalent diagnosis among hospitalized patients and many patients have unrecognized diabetes. Glycemic control in the hospital should become a priority both to enhance quality and patient safety and to reduce costs related to length of stay.

In the hospital setting insulin should be the therapy of choice for the management of hyperglycemia and basal-bolus with insulin analogue is the appropriate scheme to use for non-critical ill patients. The limitations of basal analogues as detemir and glargine include concerns related to their pharmacokinetic and pharmacodynamic properties, hypoglycemia and perception of management complexity, including rigid dosing schedules.

The unique pharmacokinetic profile of IDeg facilitates glycemic control while minimising the risk of nocturnal hypoglycemia and its pharmacodynamic properties offers a broad dosing window, allowing for flexible dose administration when required. The clinical benefits of tight glycemic control, reduced nocturnal hypoglycemia and a more flexible treatment regimen associated with IDeg may help medical doctors to address the current unmet needs of insulin therapy management in hospital and patients to overcome the barriers associated with initiation of basal insulin therapy.

\section{References}

1. Umpierrez GE, Isaacs SD, Bazargan N, et al. Hyperglycemia: an independent marker of in-hospital mortality in patients with undiagnosed diabetes. J Clin Endocrinol Metab 2002;87:978-82.

2. Brutsaert E. The clinical impact of inpatient hypoglycemia. J Diabet Complicat 2014;28:565-72.

3. Bailon RM, Cook CB, Hovan MJ, et al. Temporal and geographic patterns of hypoglycemia among hospitalized patients with diabetes mellitus. J Diabetes Sci Technol 2009;3:261-8.

4. Kerry C, Mitchell S, Sharma S, et al. Diurnal temporal patterns of hypoglycaemia in hospitalized people with diabetes may reveal potentially correctable factors. Diabet Med 2013;30:1403-6.

5. Ulmer BJ. Temporal occurrence and recurrence of hypoglycemia during hospitalization. Endocr Pract 2015; 21:501-7.

6. Cook CB, Seifert KM, Hull BP, et al. Inpatient to outpatient transfer of diabetes care: planing for an effective hospital discharge. Endocr Pract 2009;15:263-9.

7. Griffith ML, Boord JB, Eden SK, Matheny ME. Clinical inertia of discharge planning among patients with poorly controlled diabetes mellitus. J Clin Endocrinol Metab 2012;97:2019-26.

8. Moghissi ES. Addressing hyperglycemia from hospital admission to discharge. Curr Med Res Opin 2010,26: 589-98.

9. Lee Y-Y, Lin Y-M, Leu W-J, et al. Meta-analysis. Sliding-scale insulin used for blood glucose control: a metaanalysis of randomized controlled trials. Metabolism 2015;64:1183-92.

10. Mathioudakis N. A comparison of inpatient glucose management guidelines: implications for patient safety and quality. Curr Diab Rep 2015;15:13.

11. Vora J, Cariou B, Evans M, et al. Clinical use of insulin degludec. Diabet Res Clin Pract 2015;109:19-31.

12. Jonassen I. Design of the novel protraction mechanism of insulin degludec, an ultra-long-acting basal insulin. Pharm Res 2012;29:2104-14.

13. Heise T. Ultra-long-acting insulin degludec has a flat and stable glucose-lowering effect in type 2 diabetes. Diabet Obes Metab 2012;14:944-50.

14. Hollander P, King AB, Del Prato S, et al. Insulin degludec improves long-term glycaemic control similarly to insulin glargine but with less hypoglycaemia in patients with advanced type 2 diabetes on basal-bolus insulin therapy. Diabet Obes Metab 2015;17:202-6.

15. Ratner RE. Hypoglycaemia risk with insulin degludec compared with insulin glargine in type 2 and type 1 diabetes: a pre-planned meta-analysis of phase 3 trials. Diabet Obes Metab 2013;15:175-84.

16. Peyrot M, Rubin RR, Kruger DF, Travis LB. Correlates of insulin injection omission. Diabet Care 2010;33:240-5.

17. Rubin RR. 2005 Adherence to pharmacologic therapy in patients with type 2 diabetes mellitus. Am J Med 2005;118:27S-34S.

18. Randløv J, Poulsen JU. How much do forgotten insulin injections matter to hemoglobin A1c in people with diabetes? A simulation study. J Diabetes Sci Techn 2008;2: 229-35.

19. Morris AD, Boyle DIR, McMahon AD, et al. Adherence to insulin treatment, glycemic control, and ketoacidosis in insulin-dependent diabetes mellitus. Lancet 1997;350: 1505-10.

20. Anderson RT, Marrero D, Skovlund SE, et al. Self reported compliance with insulin injection therapy in subjects with type 1 and type 2 diabetes. Diabet Metab 2003;29:A275 [Abstract].

21. Peyrot M, Barnett AH, Meneghini LF, Schumm-Draeger PM. Insulin adherence behaviours and barriers in the multinational global attitudes of patients and physicians in insulin therapy study. Diabet Med 2012;29:682-9.

22. Mathieu C, Hollander P, Miranda-Palma B, et al. Efficacy and safety of insulin degludec in a flexible dosing regimen vs insulin glargine in patients with type 1 diabetes (BEGIN: Flex T1): a 26-week randomized, treat-to-target trial with a 26-week extension. J Clin Endocrinol Metab 2013;98:1154-62.

23. Meneghini L, Atkin SL, Gough SCL, et al. The efficacy and safety of insulin degludec given in variable oncedaily dosing intervals compared with insulin glargine and insulin degludec dosed at the same time daily: a 26week, randomized, open-label, parallel-group, treat-totarget trial in individuals with type 2 diabetes. Diabetes Care 2013;36:858-64. 
24. Haahr H, Heise T. A review of the pharmacological properties of insulin degludec and their clinical relevance. Clin Pharmacokinet 2014;53:787-800.

25. European Medicines Agency. Insulin degludec. Summary of product characteristics; 2013. Available from: http:/www.ema.europa.eu/docs/en_GB/document_library/EPARProduct_Information/human/002498/WC̄50 0138940.pdf Accessed: March 2015.

26. Ericsson Å, Pollock RF, Hunt B, Valentine WJ. Evalua- tion of the cost-utility of insulin degludec vs insulin glargine in Sweden. J Med Econ 2013;16:1442-52.

27. Evans M, Wolden M, Gundgaard J, et al. Cost-effectiveness of insulin degludec compare with insulin glargine in a basal-bolus regimen in patients with type 1 diabetes mellitus in the UK. J Med Econ 2015;18:56-68.

28. Evans M, McEwan P. Clinical and cost-effectiveness of insulin degludec: from clinical trials to clinical practice. J Comp Eff Res 2015;4:279-86. 